\title{
A COMPARATIVE AND ANAIYTIC COMPARISON OF THE VARIOUS IMAGES OF MOON AND THE SUN BASED ON ANCIENT ASTRONOMY IN NASER KHOSRO, ANVARI AND NEZAMI'S POEMS
}

\author{
Behnaz Shahnavazi \\ Department of Persian Literature, Zahedan Branch, Islamic Azad University, Zahedan, Iran \\ Habib Jadidoleslami (Corresponding author) * \\ Department of Persian Literature, Zahedan Branch, Islamic Azad University, Zahedan, Iran
}

\begin{abstract}
Sky and celestial phenomena has long been caused men's surprise, and has couraged humans to unravel the mysteries and secrets of the beauties hidden in it. The vast expanse of sky, incredible beauty of the stars, the glow of the moon, sunrise and sunset, all these things gradually increased the sense of interest and curiosity in mankind so that its manifestation can be seen in many artistic works. Among numerous astronomical elements, the sun moon is one of the planets which have had a beautiful reflection in poetry. Among the poets who had a special look at the moon, we can name three great Persian poets: Naser Khosro Ghobadiani, Anvari and Nezami. And also because of the fact that fifth and sixth century were two of the most productive periods in Persian literature, and Isfahan, Khorasan, Aran and Azarbayejan were regarded as the main centers of poetry and literature of these periods, that's why in this article moon's manifestation has been studied in the poems of these three poets who lived in fifth and sixth centuries. This paper aims to detect, analyze, and compare various aspects of moon based on ancient astronomy in Naser Khosro, Anvari and Nezami's poems. To achieve this purpose, first the word astronomy science, astrology, and its manifestation in Persian poetry has been studied in brief. Then moon, locations of the moon and its different manifestation in the poems of these three poets have been shown, analyzed and compared. The results of this study shows that moon had been shown in the poets of all these three poets in different forms such as showing moon in its twelve towers, cancer, Taurus, and folk beliefs about moon, eclipses.
\end{abstract}

KEY WORDS: NASER KHOSRO, ANVARI, NEZAMI, MOON AND POETRY

\section{Introduction}

Attention to sky and celestial phenomena caused men's surprise and couraged them to unravel the mysteries and secrets of the beauties hidden in them. The first result of human's efforts for obtaining knowledge about star's movements was the fact that men believed in the possibility of life on the moon, this fact caused the creation of many religious and mythical beliefs, so that many of those beliefs has a special place in customs and religious beliefs of today's human despite the passage of thousands of years. The vast expanse of sky, incredible beauty of stars, the glow of moon, sunset and sunrise gradually increased the sense of interest and curiosity in mankind so that its manifestation can be seen in many artistic and literary works of the world, so that many of the poets and writers all over the world reflects the beauties of sky and astronomy in their works. Astronomy is one of the most ancient human sciences. In the past, people considered the situation of stars effective in the condition of their lives and also their fate. "Ancient people predicted climate change, wind, earthquakes, lunar eclipse, eclipse, rain and...by their observations and their personal experiences through centuries, doing this they have formed a set of rules which were transferred generation to generation to reach us today. In any case, these ideas are common knowledge and folklore culture; therefore they have a very important situation in anthropology because their roots are in wisdom, talent, and the accuracy of the folklore. (Shakurizade, 1993; 170). In the past, people lived in a context of folk and unscientific beliefs. Ignorance about the nature and cause of objects and phenomenon leaded to astronomical thoughts or beliefs. By astrological beliefs, we mean those opinions and beliefs that ancient people have had about stars, celestial bodies, and their effects on their lives and on the elements of nature: such as the belief that sunlight cause the creation of gems like garnet and amethyst. 


\section{A COMPARATIVE AND ANAIYTIC COMPARISON OF THE VARIOUS IMAGES OF MOON AND THE SUN BASED ON ANCIENT ASTRONOMY IN NASER KHOSRO, ANVARI AND NEZAMI'S POEMS}

Many works of poets and writers which are written to reflect all aspects of human life, show astronomy and all its beauties well. So that by looking them, we are able to solve many secrets of human issues especially ancient people. With the help of literature and literary works, we can come over time and place; we can see ancient people and live with them. In Persian literary works, astronomy is reflected so much. We can name the anonymous nature, and incredibility of sky, and also ancient's belief regarding the effect of sky and stars on human fate as the reasons of poet's attention to them. Persian literature as a mirror for Irans' art and culture, have had reflected many issues regarding sky in itself from the very beginning days of its creation. So it is necessary to study this issue in different Persian literary works. And the way of their reflection, their similarities and differences in the works of different poets should be compared.

Looking at the past Persian literature, it is obvious that all poets and writers have used heavenly and celestial phenomena in their works variously. Astronomy had a very important value and it was very common among wealthy families to appoint time for their works and also to show lucky or malevolent days, so that astronomy was regarded as one of the very essential information part of each spiritual and religious figure. On the other hand, there was a folk knowledge among people against each modern knowledge, in old days, sometimes the illusionary and superstitious aspect of some sciences were supposed more important than their rational and scientific aspects and some sciences were entirely based on superstition (Mahjoob,2003:137)

Astronomy had a very important value in pre-Islamic Iran, what is left in ancient books, clay tablets, and ceramics and especially in Ilami tablets about the name of months, 300-400 words, symbols and characteristics of stars shows that astronomy knowledge goes back to long before Babylon (Ghazani, 1990:546-547).

After the arrival of Islam, not only this interest was not finished, but also its various aspects grew with time passage, and it caused the creation of different terms associated with cosmic events. "this terms penetrated into poets works gradually, and created an important connection between poetical illusions and cultural ideas, some of which is gathered in Astronomical Terms Culture Book " (Ghafelebashi and Hashemi, 2010:121).

Religious astronomy was one shape of prediction which was based on the principle that stars and planets affect terrestrial objects and individuals' fates. Today this kind of astronomy is not regarded as a science. But in past it was a kind of science to know the characteristics, situation of people and showed effects of stars and planets on them, it found a place among people over time, and some beliefs were shaped about some parts of this science. Ancient people could not find justifiable answers to their questions and what happened to them, so they tried to justify some of those events by relating them to sky and astronomy. Anyway, religious astronomy itself became a base for astronomy knowledge and religious astronomy was terminated over time by great scholars such as Abureyhan AlBiruni who did not believed in this superstitions.

Astronomy and issues related to it had a very important effect on Iran's culture; its biggest manifestation can be seen in its presence in the works of great poets and writers such as Naser Khosro, Hafiz, Anvari, Sa'di, Senaieee, Nezami and others. Poets sometimes mentioned astronomical terms in their speech as metaphor or as simile. And also they sometimes used these terms to exclude some superstitious thoughts among people. Fifth and sixth centuries were one of the most productive periods in Persian literature. Khorasan, Aran, Azarbayejan and Isfahan were regarded as the most important centers of literature and poetry in this period. In this period, Islamic culture has penetrated in all aspects of people life. Poets had always focused on the arrangement of words relying on their knowledge in scientific and literary areas and they had tried to achieve fresh and innovative themes.

Astronomy was one of the common sciences of fifth and sixth centuries. "The appearance of scholars such as alBiruni, Omar-Khayam in west and Ibn-saed and Abu-Ishagh Zarghani in east of Islamic countries is a proof to this claim. The creation of Talili-Zeyj, Malekshahi Zeyj, and Jalali calendar are among the important activities of this period" (Mahyar, 1990, 571). Learning astronomy was one of the essential things for scientists.

In this paper, we are comparing the manifestation of moon relying on ancient astronomy in Anvari, Nezami and Naser Khosro's poetry. The review of astronomy in the poems of these three poets can show their view to astronomy in Khorasani and Araghi style; it is done to show the maximum frequency of the appearance of moon will happen in which poets' works. This paper is going to answer this question: According to ancient astronomy, how and for what purposes moon was reflected in poems of Naser Khosro, Anvari and Nezami? 


\title{
A COMPARATIVE AND ANAIYTIC COMPARISON OF THE VARIOUS IMAGES OF MOON AND THE SUN BASED ON ANCIENT ASTRONOMY IN NASER KHOSRO, ANVARI AND NEZAMI'S POEMS
}

\begin{abstract}
Astronomy
Astronomy is the plural of "Najm" word meaning stars. Literally astronomy means the appearance and rising of stars and growing up of the plants. In terms of ancient knowledge, astronomy was regarded as one sector of mathematics and also a branch of arithmetic science between Muslims in which degrees, minutes, and seconds were discussed by multiplication, division, subtraction, and roots. Its subject matter was about understanding the situation of celestial bodies in relation to each other and also in relation to territorial creatures, their number, size and their movements. In fact, astronomy is a science in which the celestial bodies appearances, the rules of their true and apparent movements, sizes, distances and their natural properties is discussed.
\end{abstract}

\section{Ecliptic}

Ecliptic is the path of the annual apparent movement of sun in relation to earth in the celestial sphere. It is an imaginary circle in sky that apparently (in the eyes of the earth's inhabitants) believe sun to move around this circle in a year. This circle actually detects the circle in which earth goes around the sun which is literally named "Savabet planetarium". It seems that sun in its apparent annual movement goes through twelve constellations of stars and celestial sphere known as ecliptic. These twelve constellations of star include: transportation (lamb), Taurus (bull), Gemini (twins), Cancer (crab), Leo (lion), Virgo (cluster), Scorpios (the scorpion), Aguarius (cathment), Pisces (fish).

\section{Fifth and sixth centuries' poem}

Persian's fourth and fifth centuries' poetry is named Khorasani style. Because the first poems related to pro-Islam belongs to an area in Transoxiana and Khorasan. Of course Persian poetry at that time had a very much broader geographical range compared with the present Khorasan of today. It used to spread from north to Oxus River, from south to Sistan and from east to China.

The simplicity of language, the ability of poets, their power in combining words, and creation of innovative themes, use of few number of Arabic word, the huge number of poems, the freshness of poetry thoughts and themes, metrical transformation, prosperous lives of most poets, signing of praise poems, describing nature and...are among the characteristics of Khorasani style poetry.

Sixth century poetry: the poetry of sixth century to the end of ninth century is known as Araghi style. This style includes Mughul, Ilkhanan, and Timurid periods. The reason for its naming is the fact that after the brutal attack of Mughul, the cultural centers moved from Khorasan to Iraq. Perhaps the most important style in all periods of Persian poetry is Iraqi style. Because the greatest Iranian poets belong to this period, and the most valued literary works of Iran belong to 7 to 9 centuries.

The entrance of numerous words and combinations from local dialects into Farsi, deeper and more extensive influence of Islamic culture, increase in Arabic words and combinations, the influence of Sufi thoughts and terms in poetry, pessimism of the poets to the situation of that time due to the ravages of this period, the spread of the poetry out of courts and its spread between wider groups of people, the expression of political and social situation, criticism of the mess, the expression of personal feelings and... are among the characteristics of this period's poetry.

\section{Comparative literature}

Comparative literature which is sometimes called "universal literature" is an essentially French science. In plain language it consists of the comparative review of works which have roots in different cultural areas. In fact, comparative literature is a branch of literary criticism which discuses the literary relation of nations, different languages, and the relation between nations' literature. It is an important branch of literature which discuses the similarities and differences between literature, language and nationality of different nations. 


\section{A COMPARATIVE AND ANAIYTIC COMPARISON OF THE VARIOUS IMAGES OF MOON AND THE SUN BASED ON ANCIENT ASTRONOMY IN NASER KHOSRO, ANVARI AND NEZAMI'S POEMS}

Comparative literature can compare the literature of two or more different countries, it can also compare the literature of one area with the literature of all other areas of earth, or even it can compare the literature of different periods of one single country among the poets and writers of that country. Therefore, in this article, the poems of Naer Khosro, the poet of Khorasani style, Anvari, the poet of Iraqi-Khorasani style and Nezami, the poet of Iraqi style are compared to show different reflections of moon in their works.

\section{The hypothesis}

Our hypothesis is based on the principle that moon is manifested in the poems of the three poets; Anvari, Nezami, Naser Khosro, in various forms such as eclipse, moon's locations, brilliance of the moon and et cet. We have discussed this hypothesis by analyzing and comparing the lyrics of these three figures.

\section{Research literature}

So far numerous articles and books have been published regarding each of these three poets (Anvari, Nezami, and Naser Khosro). Also some researches have been done directly or indirectly about astronomy in the poems of these poets. But in the books, articles, theses, and other comparative studies which have been done so far, any works have been done focusing on moon in the works of these three poets. Among the works done about these poets, we can mention the below cases:

The book "Astronomy in the Works of Naser Khosro" written by Zahra Hesariani. The writer has discussed Naser Khosro's beliefs, the poet of fifth century (391-481), regarding the effects of stars and astronomy in universe. The article "astronomical beliefs in Nezami's poetry" written by Fatemeh Elahi. This article has discussed folk beliefs in three works of Nezami;"Khosro and Shirin', Lili and Majnoon', and "Haft Peykar". The Thematic and Structural comparative thesis done on Anvari and Khaghani's poetry" written by Roghaye Hedayyati Sani and many more studies which we cannot name in the article.

\section{Results}

\section{Moon}

Humans used to benefit moon's regular rotation as calendar, particularly in agriculture. Passengers and sailors also used the presence and moon's light for orientation and navigation. Moon also was presented in myths of many nations. In some cultures, people worshiped moon as a god.

In Persian literature, moon has had a very prominent place. It was always a symbol for beauty and brilliance. Using moon to describe and to show similarity is so common among Persian poets, that you can find few poets who had not used moon for these purposes.

Moon is also named "Maj, Mas, and Mahir" in Farsi. In Iranian's older language, it was seen as "Mang" too. In Persian literature, the words glowing, nocturnal, unwashed face, and merciful are attributes of moon, and the terms lights, flame, silver circle, circle glass, cup, tablets, bergamot, apple, sandals, cotton balls, and claw are among moon's evocations.

Moon is the nearest planet to earth. The beautiful image which humans have in their mind regarding moon has always had a great influence in their imagination and their feelings. "From astronomical aspect, moon is a planet which is dependent to earth, the time circle needed for its rotation is 33/27 days, and therefore always one side of the moon is toward earth. Moon has had a prominent role in Iran's' ancient myths, in Zoroastrianism, it was regarded as animals guard and the twelfth day of each solar month was named moon" (Mashhur, 2009, 75).

In moon's definition, the following words are mentioned in Dehkhoda's dictionary. In many parts of Iran, especially in popular opinion, moon and sun are man and woman who love each other. The spots on moon are the effect of sun's hand which has had put his muddy hand on moon's face as a result of envy. Ancient people believed that if a 


\section{A COMPARATIVE AND ANAIYTIC COMPARISON OF THE VARIOUS IMAGES OF MOON AND THE SUN BASED ON ANCIENT ASTRONOMY IN NASER KHOSRO, ANVARI AND NEZAMI'S POEMS}

crazy person look at moon, his craziness will increase.

In the past, people also had some other beliefs about moon. "They believed, at ecliptic times, moon or sun were captivated by Jinns, they started beating drums and shooting guns to release moon or sun." (Mirnia, 1990, 241). They believed moon's light causes the growing of plants and the color of flowers. " the common belief was that moon will cause the color of flowers, so poets called moon Mashate (meaning cosmetologist) or Sabagh, meaning the painter of flowers" (Mosafa, 2002, 696).

\section{Moon's crescent manifestation in Nezami, Anvari and Naser Khosro's poetry}

Ancient astronomers regarded moon as the nearest planet to earth. By the appearance of Batlimuce and the publication of "Mojasti", this belief became a real fact and moon was known as the first star of the multiple spheres (seven, eight, and nine) and this opinion was accepted by all astronomers. Accordingly, they had expressed various opinions about moon, they believed moon's home is in Cancer, its appearance is in Taurus, and its demise is in Capricorn. They also believed that travelling is not permissible when moon is in Scorpion and when it is in Gemini, intending to do something was not permissible too.

We should note that sun is shining itself, but it is not the case about moon. We see moon, because of sun's shining at it. We see full moon, if that side of moon which is toward us be exposed to sunlight. If sunlight shines to only some part of the moon, we saw moon as a thin crescent, half-moon or like a round circle depending on the amount of shined light. This optical phenomenon is called different phases of the moon.

When moon is placed completely opposite to sunlight, it fades in intense radiation of sun and we cannot see it. This situation is called New Moon. Anyway, all these astronomical changes lead us to see moon in different shapes; from a thin crescent in first days of the month to a full-moon in the fourteenth night of the month. This beautiful manifestation of moon in the sky has caused many beautiful poems in Persian literature especially in the works of Nezami, Anvari and Naser Khosro. In some of the below cases, poets have likened their beloved one to moon in respect of their beauty.

The image of the laugh of the crescent has been portrayed in the sky (Nezami, 1995: 538). "Lili and Majnoon". Your face is as beautiful as sun and moon, your lips are as sweet as sugar and honey (Anvari, Sonnet, 11) - the book of poem. Your beauty is like the fourteenth- night moon, your beauty is like Azeri idol (Anvari, sonnet No.11) the book of poems.

Anvari and Nezami have superiority over Naser Khosro in describing moon and also in the creation of beautiful images and metaphors by using moon. Their similes are very beautiful and in some cases the similes are their own innovations. One of the beautiful descriptions of moon in Persian literature relates to the appearance of the crescent of moon for Eid al-Fitr declaration. The appearance of Shawwal crescent was necessary to declare Eid. Poets have used this event and have created beautiful images in this respect. Such as the poem by Anvari:

He said" say God and worship God

I said " oh the crescent of Ramadan" (Anvari, Ode No.134)-the book of poems.

\section{Moon's location}

Since third century AD, many astronomers relied on a set of stars which were near to moon and the planetary alignment to determine moon's location in sky. They wanted to determine instances of moon's orbit in sky. They believed "at any time in day or night, there are fourteen locations above the horizon and also fourteen locations below it, and when one of the locations rise in west, the fifteen locations falls in east. And it is clear that from the rise of one location to fall of the other location, it will last 13 days" (Alfonso Nalyno: 1970, 143).

Past astronomers categorized these 28 locations in four groups of spring, summer, autumn, and winter. They have chosen these names for the locations: Aldebaran, Soraya, Jibhe, Spica, Boothes, Rosemary, Saad Zabh, Saad al Seud. Nezami has named most of moons location in his poem:

Quake has happened in the sphere, from the shape of towers and moon's location in sky. The image of the crescent 


\section{A COMPARATIVE AND ANAIYTIC COMPARISON OF THE VARIOUS IMAGES OF MOON AND THE SUN BASED ON ANCIENT ASTRONOMY IN NASER KHOSRO, ANVARI AND NEZAMI'S POEMS}

of the moon is portrayed in the heaven. The Cow constellation is like sea's cow, it is like a gem in Soraya. June has seen on a bed made of two bodies. Crab is like forest's cubits whose nail is removed. Jibhe has made sky as shining as one hundred lights by its beauty. The hearth of Lion constellation is shining as a result of the presence Lion, like the fire of flares which are shining. Like generous people, it has spread its light in the sky. Like a generous person who put bread in the bowl of orphans. Mizan has spread its light like a wise man that spread his knowledge by his tongue. Bootes is like a hunter who is riding two hunting dogs. Scorpion has superiority over the bows. Baldeh has had all the blessings under its presence. Joday has cut his head like a goat, because it has heard the myth of the goat. Zabeh has closed its mouth, because of its fear and has taken the leash of Sa'ad. (Nezami, 1934, 174-176). -"Lili and Majnoon"

Anvari has also mentioned some of these locations:

My voice in praising you will arrive to Nasre, in your praise, I will sing poem after poem. (Anvari, Ode No.181)The book of poems

It has turned from a fly to an eagle, it has gone up to spica from a very low position (Anvari, sonnets, 466) - the book of poems

Poets have paid more attention to some moon's locations in comparison with other locations; therefore we will mention a few of them below.

\section{Bootes}

Bootes is the fifth location of northern constellation which is also called "Sayah", "Beghar", "Gavcheran", "Hares alSema", and "Hares al-Shemal". Booths represents a hunter, holding the leash of two dogs in one of his hands while riding a lion. Bootes is like a hunter riding a lion while having the leash of two hunting dogs in its hands (Nezami, 1934: 174-176) Lili and Majnoon Booths constellation is not mentioned in Anvari and Naser Khosro's poetry, but it is mentioned in Nezami's poems several times.

\section{Aldebaran}

Debor means entering from the back. This star is named Aldebaran, because it comes out from the back of Soraya. It is also named "Tabe al-Najm", "Tali al-Najm", and"Hadi al-Najm". Because of the fact that it is placed in the center of Taurus constellation, it is also called "Eyn al-Taurus", meaning the eyes of Taurus constellation.

Aldebaran has the fourth location among Moon's locations. Astronomers believe that it is malevolent. In the past, astronomers regarded the rain which came in this location, to be malevolent and assumed it to be an introduction for drought.

The intention of Aldebaran is not toward nullity, if you are a friend, know the reality of Aldebaran (Naser Khosro, 1976:544) - the book of poems Aldebaran constellation is used just in Anvari and Naser Khosro's poetry, Nezami has not used it in his poems at all.

\section{Jibhe}

The tenth location of moon is called Jibhe which has had much manifestation in Persian Poetry. Jibhe constellation is manifested in Nezami's poetry, Anvari and Naser Khosro had not mentioned it in their poems. Jibhe has lightened the sky by its beauty as if there is one hundred lights in the sky (Nezami, 1934: 174-176). 


\title{
A COMPARATIVE AND ANAIYTIC COMPARISON OF THE VARIOUS IMAGES OF MOON AND THE SUN BASED ON ANCIENT ASTRONOMY IN NASER KHOSRO, ANVARI AND NEZAMI'S POEMS
}

\author{
Rameh Spica and Azal Spica
}

Astronomers have named the red shining star which they have observed out of Bootes constellation as "Rameh Spica". Of course "Azal Spica is placed in the fourteen location of moon and it is not regarded as one of Scorpion's constellation stars.

Brightness and high position of these two Spicas are among the most important motivations which have caused poets to mention them in their poems so much.

All three poets have mentioned these two Spicas in their poetry but Anvari has used it more than the others.

\section{Eklil}

Astronomers have named the three stars which are placed in front of Scorpion constellation as Eklil; they are placed in a line. This constellation is the seventeenth location of the moon. In Persian poetry, when we say the seventeenth location, we mean "Eklil", we should not interfere it with "Northern Eklil" or "Southern Eklil".

Eklil is the heart of the crown, it has superiority over scorpion (Nezami, 1934: 175_- "Lili and Majnoon

Last night the sun of sky, Eklil was seen. I hope both of them to be lucky (Anvari, Ode No. 122).

"Eklil Constellation" is manifested in Anvari and Nezami's poetry. Naser Khosro had not used it in his poems.

\section{Baldeh}

"Baldeh is the twenty-first location of moon. This location is the place between "Na'ayem" and "Sa'ad Zabeh" in which there vacuum space. It is among those locations of moon that poets have paid great attention to it and have mentioned it more than other locations of moon. But in the poetry of the three desired poets, we can see its manifestation just in Nezami's poems.

\section{The reflection of lunar eclipse in Persian Poetry}

The placement of moon in the shadow of earth is named lunar eclipse. The darkness of half of the moon or even its whole darkness has lead poets to create beautiful images by their innovative minds. Therefore there are many beautiful verses in this regard in our poetry. Lunar eclipse is another phenomenon which is just reflected in Anvari's poetry. Naser Khosro and Nezami had not mentioned it in their poems.

\section{The community of moon and sun or "Mehagh"}

Sun and moon will get together at the end of each lunar month in one single tower, one single minute and one single degree, this phenomenon is called community. In this situation moon will be placed under the radiations of sun, and it causes it to be invisible. The time period in which moon is located under sun's radiation is called community. And Arabs have named it "Serar"(meaning hidden), because it is hidden beneath the sun's radiation. Also it is named "Mehagh". Some astronomers regard this phenomenon to be malevolent. The brilliance of your face has superiority over Mehagh, your beauty will remove the intoxication of the drunken (Anvari, Ode No.78) the book of poem.

\section{The effect of moonlight on canvas}

The ancient people believed that moonlight will cause cotton to be spoiled. This issue is reflected in Anvari and Nezami's poetry, but Naser Khosro had not mentioned it in his poems.

Moonlight will spoil cotton, but her beautiful moon-like face has not any defect (Nezami) Khosro and Shirin)

How much is remained to your appearance, my heart is like a cotton which is placed under moonlight (it is spoiling) (Anvari, Ode No.9), The book of poems. 


\title{
A COMPARATIVE AND ANAIYTIC COMPARISON OF THE VARIOUS IMAGES OF MOON AND THE SUN BASED ON ANCIENT ASTRONOMY IN NASER KHOSRO, ANVARI AND NEZAMI'S POEMS
}

\author{
The crazy people got crazier by looking at moon
}

In the past, people believed that looking at moon will cause the disturbed people to get more disturbed. This issue has a very beautiful reflection in Persian Poetry. This phenomenon is not mentioned in the poetry of Anvari and Naser Khosro, but Nezami has reflected it in his poems.

He cannot turn toward me, because the crazy people are not permitted to look at the moon. (Nezami, ode No.13).

*the verse mentions the belief that disturbed people cannot look at the moon, doing so, they will get more disturbed (Nezami, 1934: 105) - "Lili and Majnoon"

Like a crazy person who has seen the moon, sometimes he stands up and sometimes sits down.

*again it has mentioned the idea that crazy people are not permitted to look at the moon.

It's better not to make me happy by seeing you, because the crazy one cannot look at the New Moon (Nezami, 1934: 77).

\section{Moon as a guide}

Ancient people believed that moonlight is a guide for passengers and for those who have lost their ways. Muslims also had a strong believe in this regard, there is also one verse of the "Holy Koran" which mentions this phenomenon "God is the one who has placed stars for you to find your ways in the darkness of land and see, we surely guided those who know" "Verse 97 of Sura Anam). Anvari has a poem which reflects this issue beautifully.

Moon came out as a guide and Venus came out as a beloved, it will guide you in all the way (Anvari, Ode No.189) the book of poem

\section{Moon's Location in Cancer Constellation}

Astronomers have divided the twelve towers of "Zodiac" into two parts; they have specified six towers to moon and the other six to sun. They have specified the towers beginning from the start of Leo Capricorn to the end of Goat to sun, and from the beginning of Aquarius to the end of Cancer to moon. Accordingly, they have regarded Leo Capricorn as sun's location; they also have assumed Cancer Capricorn as moon's location. They have allocated the five remaining towers of moon and sun to other planets based on astronomical data. Nezami has reflected this idea that moon's location is in Cancer Capricorn in one of his poems.

Moon entered into its towers, as if it is coming to its castle (Nezami, 1964:383) - "Khosro and Shirin."

\section{The dignity of moon in Taurus tower}

Ancient astronomers regarded some towers as the position of dignity for some planets. They assumed these places based on astronomical information and accurate grading. Accordingly the dignity of moon is considered in Taurus tower, Nezami has mentioned this issue in one of his poems.

Whenever Venus is placed in Taurus, and Jupiter in Sagittarius, they are placed in their heavenly location , (it's time of their dignity) (Nezami, 1964: 99).

*it has mentioned the dignity of moon in Taurus.

\section{Moon in Scorpion}

In past, people assumed the entrance of moon into Scorpion to be malevolent. They especially believed that travelling is not permissible in this situation. This belief is reflected in Persian Poetry. In the poems of Anvari, Nezami and Naser Khosro, there is not any direct mention to this issue, but Anvari has reflected the malevolently of Scorpion in their poems.

Your revenge is as malevolent as Scorpion's

Your kindness is as good as the luckiness of Scales (Anvari, Ode, No145) - the book of his poems

*it has mentioned the ominous nature of Scorpion

Nayerin or sun and moon together

The brilliance and indefinable beauty of moon and sun has long been in the focus of people especially astronomers and poets have created beautiful images and meanings regarding these two. This issue has been reflected beautifully 


\section{A COMPARATIVE AND ANAIYTIC COMPARISON OF THE VARIOUS IMAGES OF MOON AND THE SUN BASED ON ANCIENT ASTRONOMY IN NASER KHOSRO, ANVARI AND NEZAMI'S POEMS}

in the poetry of all three poets; Anvari, Nezami, and Naser Khosro. But it is seen in the poetry of Anvari more than the two others. Anvari has written a whole ode in this regard, he has brought moon and sun together in all its verses to praise it.

Sadness and happiness of the beloved, fear and hope of the beloved

Moon and sun, the creator of night and day (Nezami, 1996:125).

*this verse has mentioned to moon and nights together (Nayerin) as the creator of nights and days.

Her face is more beautiful than the sun

She has given of her beauty to moon and sun (Nezami, 1995:151)

*here again the verse has mentioned moon and sun together (Nayerin) and says his beloved is more beautiful than moon and sun.

As moon has the sun shining on his face, it will turn to a luminous crescent (Naser Khosro, Ode No.136) - the book of his poems

*here again moon and sun have come together (Nayerin).

Since you have been born, no one has seen any other mother giving birth to moon and sun together (Anvari, Sonnet No. 19)- the book of his poems.

*in this verse, the poet has mentioned Nayerin again.

Moon and sun with all their beauties, are the servant of your beautiful face. (Anvari, Sonnet No.171). The book of his poems

*here again, the poet has mentioned moon and sun together.

\section{Discussion}

Naser Khosro, Anvari and Nezami, all lived in fifth and sixth century, a period which can be assumed as golden ages of poetry and literature in Iran. Many great Persian poets appeared in this period. In that time, innovation and the creation of beautiful poems have got such a great importance among poets that they tried to get superiority over each other. Accordingly little by little the entrance of scientific information into poems became a sign of superiority among poets. Astronomy was among those sciences that poets tried to enter it into their poetry. One of the most beautiful astronomical images in poetry is the image of moon in the poems of Anvari, Nezami and Naser Khosro. In a comparative study of different reflections of moon in the poems of Nezami, Anvari and Naser Khosro, the following results were obtained.

- Based on ancient astronomy, moon is reflected in the poems of Anvari, Nezami and Naser Khosro variously including the brightness of moon, its crescent, and also various image creations of moon such as moon's location, moon in its twelve towers, eclipse, and the presence of moon and sun together.

- Among the different images of moon, there are some ancient and to some extent superstitious beliefs in the poetry such as the beliefs about the effect of moon on cotton, the belief that says the crazy people got more crazy by looking at moon, and also the belief about its being guide for passengers.

- Referring to moon and sun together (Nayerin) is reflected in the poetry of Anvari more than Nezami or Naser khosro's, Anvari has a whole poem in this respect.

- The frequency of the use of moon in creation of beautiful images is seen in the poetry of Anvari and Nezami much more than Naser Khosro's.

- In the creation of images by using moon, the only towers which are reflected are Cancer and Taurus.

- The images in Anvari's poetry are much more in praise of the beloved in comparison with Nezami and Naser Khosro.

- The reference to most locations of moon is seen just in Anvari and Nezami's poetry and Naser Khosro has mentioned them less.

- The frequency of the use of moon and its different locations especially Eklil is seen in the poetry of Anvari much more than Nezami and Naser Khosro's. 


\section{A COMPARATIVE AND ANAIYTIC COMPARISON OF THE VARIOUS IMAGES OF MOON AND THE SUN BASED ON ANCIENT ASTRONOMY IN NASER KHOSRO, ANVARI AND NEZAMI'S POEMS}

\section{References}

Anvari, Ouhad al-Din Ali ibn Mohammad. (1968). Anvari's poem, volumes I and II, by Mohammad Taghi Modares Razavi's effort. Tehran: Book Publishing Firm.

Anvari, Ouhad al-Din Ali ibn Mohammad. (1993). Anvari's poem, volumes I and II, by Mohammad Taghi Modares Razavi's effort, Third edition. Tehran: scientific and cultural publishing company.

Anvari, Ouhad al-Din Ali ibn Mohammad. (1993). Anvari's poem, the efforts of Pariz Babaie (1st ed.). Tehran: Negah Publication.

Elhami, Fatemeh. (2009). Astrological Beliefs in Nezami's Poetry, Hakim Nezami's regional conference. Tehran: Islamic Azad University of Islam-shahr.

Biruni, al-Abu Reyhan Mohammad ibn Mohammad. (1983). Reviewed by Jalal al-Din Homaie. Tehran: Babak Publication.

Biruni, al-Abu Reyhan Mohammad ibn Mohammad. (1983). Reviewed by Jalal al-Din Homaie. Tehran: National Works Publication Association.

Hesariani, Zahra. (2011). Astronomy in Naser Khosro's poetry (1st ed.). Tehran: Loutus Publication.

Kharazmi, Mohammad ibn Ahmad. (2004). Meftah al-Olum, translated by Hossein Khadiv Jam. Tehran: cultural Academic Press.

Shakurizade, Ebrahim (1983). Folk in Khorasan. Journal of Litreature College, 3(4), 170-175.

Sufi, Abdul Rahman. (1972). Sovar al Kavakeb, translated by Khaje Nasir Tusi, the efforts of Moez al-din Mahdavi. Tehran: Iranian Cultural Foundation Publication.

Ghazani, Sarafraz. (1990). Astronomy Knowledge of Ferdowsi ( $1^{\text {st }}$ ed.), by Gholam Reza Setoode's effort. Tehran: Tehran University Press.

Ghafele Bashi, Seyed Esmaeil and Seyed Ali Hashemi. (2010). "especial application of arstonomical terms; one of the charesteristics of Ferdowsi's poetry, Journal of Persian Prose and Poetry styles, 3(7), 119-139.

Mahyar, Abas. (2015). Ancient Astronomy and its Reflection in Persian Litreature (2 $2^{\text {nd }}$ ed.). Tehran: Information Publication.

Mahyar, Abas. (1990). A Look at Stars and Heavens. Journal of Faculty of Litreature and Humanities of Mahhad University, 23(3-4), 571-593.

Mahbub, Mohammad Jafar and Hasan Zolfaghari. (2003). Iranian Folklore Litreature: Proceedings of Legend and Customs of the Iranian People. Tehran: Cheshme Publication.

Mosaffa, Abolfazl. (1987). A Glossary of Astronomical terms of Iran, Tabriz, Iranian History and Culture institution publication.

Naser Khosro Ghobadiaani, Abu-Moein. (1976). Naser khosro's poetry. The efforts of Mojtaba Minavi Tehrani and Mahdi Mohaghegh, Tehran: Tehran University Publication.

Naser Khosro Ghobadiani, Abo-Moein. (1969). Roshanaie Name (the appendix of Naser Khosro;s poetry), the book of poetry, Corrected by Seyed Nasrolla Taghavi with Seyed Hasan Taghizade's introduction, the efforts of Mehdi Soheili, Tehran: Offset Publication. 


\section{A COMPARATIVE AND ANAIYTIC COMPARISON OF THE VARIOUS IMAGES OF MOON AND THE SUN BASED ON ANCIENT ASTRONOMY IN NASER KHOSRO, ANVARI AND NEZAMI'S POEMS}

Naser Khosro Ghobadiani, Abo-Moein. (2001). The book of Naser khosro's poetry (including Roshanaie Name, Sa'adat abad, Odes and Cross-sectional) ( $2^{\text {nd }}$ ed.). The efforts of Seyed Nasrollah Taghavi, Introduction and Description by Seyed Hassan Taghi zadeh, corrected by Mojtaba Minavi. Tehran: Moein publication.

Naser Khosro Ghobadiani, Abo-Moein. (2001). "The book of Naser khosro's poetry" (including Roshanaie Name, Sa'adat abad, Odes and Cross-sectional), the efforts of Seyed Nasrollah Taghavi, Introduction and Description by Seyed Hassan Taghi zadeh, corrected by Mojtaba Minavi, Seconfd edition, Tehran: Moein publication.

Nasroldin Tousi, Mohammad ibn Mohammad. (1984). Tansoukh Name Ilkhani ( $1^{\text {st }}$ ed.). The efforts of Mohammad Taghi Modares Razavi. Tehran: Information publication.

Nezami Hakim Elias. (1964). Eghbal Nameh, the efforts of Vahid Dastgerdi. Tehran: Academic publication.

Nezami, Elias. (1964). Khosro and Shirin, the efforts of Vahid Dastgerdi, Tehran: the corporation company for the Publication of Iran's Book and Scientific Publishing Institution.

Nezami, Elias. (1964). Sharaf nameh of Hakim Nezami Ganjeie, the efforts of Vahid Dastgerdi, Tehran: Academic Press Institution.

Nezami, Elias. (1934). Leili and Majnoon, Corrected by Vahid Datgerdi, Tehran: Academic Press Institution.

Nezami, Elias, Makhzan al-Asrar, Corrected by Vahid, Dastgerdi. Tehran: Academic Press Institution.

Nezami, Elias. (1995). Koliat of Hakim Nezami Ganjeie, Vahid Dastgerdi, the efforts of Parviz Babaie, Tehran: Rad Publication.

Hedayati Sani, Roghaye. (2010). The Thematic and Structural Comparision of Anvari and Khaghani's poetry, Master thesis, Faculty of Litreature and Humanities, Tarbiat Moallem University of Sabzscorpionr.

\section{Contact details of the authors \\ Behnaz Shahnavazi \\ Department of Persian Literature, Zahedan Branch, Islamic Azad University, Zahedan, Iran \\ Email: bshahnavazi60@gmail.com}

Habib Jadidoleslami, Corresponding author

Department of Persian Literature, Zahedan Branch, Islamic Azad University, Zahedan, Iran 